\section{Solvent Systems for Silica-gel Column Chromatography of Indole Derivatives}

AN earlier paper ${ }^{1}$ described a method for separating a number of indole derivatives and auxin-like substances in plant extracts, using silica-gel partition columns and petroleum ether: $n$-butyl alcohol solvents used with a step-wise elution technique. Further investigations, the results of which are reported here, have extended this technique to include a number of other useful solvent mixtures.

Most eluting mixtures consisted of a more polar solvent that had been saturated with $0.5 \mathrm{M}$ formic acid, and a nonpolar one. A few consisted only of the acid-saturated polar constituent. The column, described in detail elsewhere ${ }^{1}$, was prepared by hydrating $8.0 \mathrm{~g}$ of silica gel with $5.0 \mathrm{ml}$. of $0.5 \mathrm{M}$ formic acid, then slurring the hydrated silica gel with the eluting solvent and pouring into a glass tube $14 \mathrm{~mm}$ internal diameter. The column was about $13 \mathrm{~cm}$ high after it was packed by applying air pressure from a hand squeeze bulb. Approximately $5 \times 10^{-7}$ moles of each indole derivative were chromatographed and collected in 3-ml. fractions on a fraction eollector. When mixtures of indoles were chromatographed it was often necessary to use a step-wise elution technique in which increasing concentrations of the more polar constituent were utilized in order to obtain a satisfactory separation. Each fraction was taken to dryness in the test tube in which it was collected in vacuo by use of a rotating evaporator (Rotary Evapo-Mix, manufactured by Buchler Instruments, Inc., Fort Lee, New Jersey). The indoles were afterwards detected with the Gordon-Weber modification of the Salkowski reagent ${ }^{2}$.

Most of the solvent mixtures used $n$-hexane as the nonpolar phase. Hexane does not cause column cracking at elevated laboratory tomperatures as does the petroleum ether, b.p. $30^{\circ}-60^{\circ}$, used in earlier work ${ }^{1}$. The hexane solvent mixtures are listed in Table 1, and their chromatographic properties with seven indoles of widely varying solubility characteristics in Table 2. As a group the alcohol-hexane mixtures were the most versatile. At a given concentration they could elute a particular indole more readily than any of the other solvents. With one or two exceptions they were able to separate the seven indoles listed in Table 2. A definite inforiority of one alcohol over another one was not established, with the exception of hexyl alcohol, and possibly $n$-butyl alcohol, where their higher boiling points may be objectionable. The ester-hexane mixtures were intermediate in their ability to elute the indoles. They generally effected elution and separation of all the indoles excopt tryptophan and tryptamine. All but two of these esters havo boiling points appreciably lower than the alcohols. This is a distinct advantage in laboratorios not equipped for efficient evaporation of liquids from test tubes. Butanonehexane was a slightly stronger oluting solvent than the esters; it could elute tryptophan and tryptamine. Chlorinated hydrocarbon-hexane mixtures were least satisfactory as a group. Methylene chloride, chloroform, and 1,2-dichloroethane in high concentrations were able to olute all the indoles of Table 2 except tryptophan and tryptamine. Carbon totrachloride and trichloroethylene were able to efficiently elute only othyl indoleacetate and indoleacetonitrile, and would thus appear to have little value as eluting solvents for silica-gol column chromatography of indole compounds. In no case did any of the chlorinated hydrocarbons resolve ethyl indoleacetate and indoleacetonitrile.

The choice of the non-polar constituent does, of course, markedly affect the elution pattern. Benzene with $n$-butyl alcohol, for example, eluted ethyl indoleacetate and indoleacetonitrile much more readily than did $n$-hexane. Evon closely related non-polar solvents could
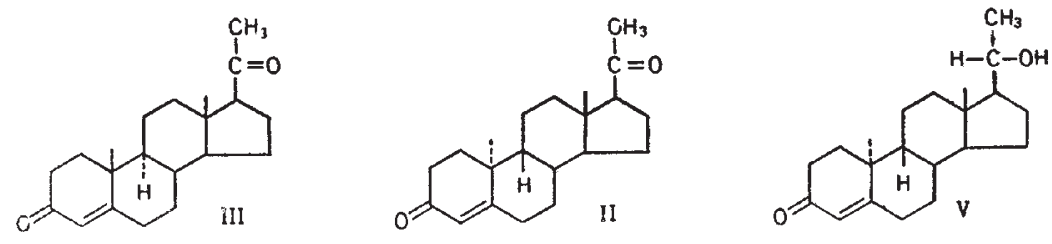

\section{Metabolism of some Progestationally Active $9 \beta, 10 \alpha$-Steroids in Man}

IN 1960 Reerink et al. ${ }^{1}$ announced a now class of hormonally active steroids named 'retro-steroids'. This class is characterized by the $\beta$-position of the C-9-hydrogen atom and the $\alpha$-position of the $\mathrm{C}$-10-methyl group.

In elinical trials two members of this class, 6-dehydro$9 \beta, 10 \alpha$-progesterone (generic name, 'Dydrogesterone') (I) and $9 \beta, 10 \alpha$-progesterone (II), were found to exert a markedly progestational activity when administered able 1. SOME Solvents USED For the SHica-gel Column Ceromato-

$$
\begin{aligned}
& \text { n-Hexane : methylene chloride } \\
& n \text {-Hexane }: \text { chloroform } \\
& n \text {-Hexane }: \text { carbon tetrachloride } \\
& n \text {-Hexane }: 1,2 \text {-dichloroethane } \\
& n \text {-Hexane }: \text { trichloroethylene } \\
& n \text {-Hexane : } 2 \text {-butanone } \\
& \text { n-Hexane : methyl formate } \\
& n \text {-Hexane : ethyl formate } \\
& n \text {-Hexane : methyl acetate }
\end{aligned}
$$

Table 2. ABItity of Chromatography Solvents to kldte Indole CIVES FROM SILICA GEL COLUMNS

Concentration of solvent in $n$-hexane required for hydrocarbons Esters and

Ethyl indole-3-acetate

Indole-3-butyric acid

Indole-3-acetic acid

Tryptophan

$100 \%$ to not eluted

not eluted

$100 \%$ to not eluted

$0.5-1 \%$
$5-10 \%$
$5-10 \%$
$25-50 \%$
$100 \%$
$100 \%$

Using the solvent systems above, the indoles were generally eluted by $50 \mathrm{ml}$. or less of solvent and came off the column as sharp peaks in volumes column when quantities of $100-200 \mathrm{ml}$. of the solvents were used. (b.p. $30^{\circ}-60^{\circ}$ ) with 0.2 per cent n-butyl alcohol were able kely concentration was unable to do so.

eluted the seven indoles in the same order, if indeed they eluted and separated them at all. That order was ethyl indoleacetate, indoleacetonitrile, indolebutyric acid, inmine. in a particular problem are not likely to be exactly those however, to guide the investigator towards a wise choice $r$ his own circumstances.

This work was carried out while the author was State Agricultural Experiment Station, Cornell University, Geneva.

Department of Pomology, Cornell University, Ithaca, New York.

1 Powell, Loyd E., Plant Physiol., 35, 256 (1960)

${ }^{2}$ Gordon, S. A., and Weber, R. P., Plant Physiol., 26, 192 (1951).

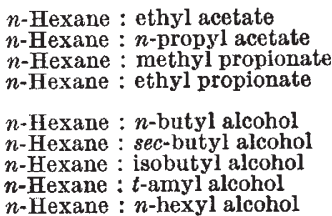

$100 \%$ to not eluted

give different results; $n$-pentane and petroleum ether acetonitrile, whereas $n$-hexane in similar or any other

purposely omitted since the substances to be dealt with 